Adrenocortical Carcinoma, New Engl. J. Med., 257, 1153.

KorNel, L. (1959): An Improved Rapid Method for Free and Conjugated 17-hydroxycorticoids in Urine, Metabolism, 8, 432.

LisSer, H., and Escamilla, R. E. (1957): 29. Congenital Adrenal Hyperplasia, Atlas of Clinical Endocrinology, p. 240, London: Henry Kimpton.

Logan, R. W., and McMillan, N. L. (1964): Adrenocortical Hyperactivity - Two Interesting Cases, Postgrad. med. J., 40, 604.

LoRAINE, J. A. (1949): The Estimation of Chorionic Gonadotrophin in the Urine of Pregnant Women J. Endocr., 6, 323.
MatTingly, D. (1962): A Simple Fluorimetric Method for the Estimation of Free 11-hydroxy- 윽 conticoids in Human Plasma, J. clin. Path., 15, 374. $\frac{3}{8}$

MoxhaM, A., and NABARRo, J. D. N. (1956): Urinary $\varrho$ Glucocorticoid Excretion, J. clin. Path., 9, 351.

Perlhoff, W. H., and HadD, H. E. (1957): Adreno- $\vec{\Rightarrow}$ genital Syndrome "Virilising Type" in an Adult $\stackrel{\text { S }}{+}$ Male: A Case Report,Amer. J. med. Sci., 234, 441.음

THORN, G. W. (1963): Cecil-Loeb Textbook of $\frac{C}{0}$ Medicine. 11th Edition. Edt. by Beeson, P. B., and $\frac{\bar{c}}{\mathrm{~s}}$ McDermott, W., p. 1402. Philadelphia and London: W. B. 'Saunders.

WYK, J. J. V. (1962): Textbook of Endocrinology. 3rd Edition. Edit. by Williams, R. H., p. 545. Philadelphia and London: W. B. Saunders.

\title{
A CASE OF "SEIZURES INDUCED BY MOVEMENT"
}

\author{
B. W. LEWIS, M.B., B.S. \\ D. K. Williams, M.R.C.S., L.R.C.P.
}

R. B. Woodd-Walker, M.B., B.Chir.*

Barnet General Hospital.

THE phenomenon of seizures precipitated by movement has been recognised at least since 1901 when Gowers described three patients, but it is rare. Mathews (1958) reported four cases of "tonic seizures" apparently occurring in the course of disseminated sclerosis, three of which began with movement, walking, turning over in bed or overbreathing. In his discussion of the causation he considers central tetany and excitation or inhibition of the pyramidal or extrapyramidal system by discharge from a subcortical focus, a supplementary motor area or brain stem. The disorder has also been found in association with epidemic encephalitis as described by Wilson (1930) and by Sterling (quoted by Wilson). Twelve cases with no other disease were collected by Lishman, Whitty and their colleagues (Lishman, Symonds, Whitty and Willison, 1962; Whitty, Lishman and FitzGibbon, 1964). They also reviewed the literature and supported the view that it is a form of "reflex epilepsy", though it is unknown whether from discharge from the basal ganglia or the premotor cortex. In support of the latter, Falconer, Drive and Serafetinides (1963) cured a similar, but not identical case, by excision of a scar from the cortex.

We here describe a case which exemplifies most of the features of this bizarre condition because it easily may be thought to be hysterical but, if recognised, can be treated effectively with anticonvulsants.

*Present address: St. Mary’s Hospital, Portsmouth.

\section{Case Report}

The patient was a fat messenger boy aged $\frac{0}{10}$ years. He had no significant past history until two weeks before admission when, while riding bicycle, he experienced an unpleasant sensation "like electricity" in his left arm which lasted about half a minute. It was followed by generalised $ֶ$ sweating; there was no incontinence nor loss of $\mathbb{D}$ consciousness. Since then he had had several more attacks, averaging about three a day. They always $\overrightarrow{\overrightarrow{0}}$ affected his left side only and were transient. In 3 a typical attack, he felt it starting about ten $\bar{T}$ seconds before his hand clenched; then the elbow flexed and he pressed his index finger against the teeth. Sometimes the left leg was involved similarly윽 with inversion of the foot. The sensation spread 3 . to the ear but the face was not affected. After some $\frac{}{5}$ 45 seconds the spasm ceased and he relaxed, 3 . obviously relieved. He had found that it helped to hold his arm straight with the right hand.

In the ward he lay still in bed as he found that the spasm was precipitated by movement. At length he was persuaded to get up which he did, anxiously $>$ hyperventilating, and after two steps he had an o attack as described. In spite of the appearance of strong muscular contraction, it was easy for an $\mathbb{N}$ observer to straighten the fingers. In between attacks clinical examination was normal.

Investigations: CSF, WR and skull X-ray were $\underset{\omega}{\mathcal{E}}$ normal. Hb and ESR normal; WBC 12,000, $13 \%$ O eosinos (this is not usually noticed). Angiography was thought unjustified in view of the family history.

Treatment was begun with ohlordiazepoxide $\mathbb{\Phi}$ (Librium) 10 mg. t.d.s. bcause it has a mild $\stackrel{?}{+}$ anticonvulsant as well as a sedative effect. After 0 two days he had no more seizures. Electroence- 0 phalogram on the third day showed that there was $\underset{\mathbb{D}}{\mathbb{D}}$ a mild overall dysrhythmia of a nonspecific variety, 
without focal or epileptic features. Now he is also on phenytoin and remains well three months later.

The Father. The father, aged 53, said that he thought he was acquainted with the sort of attacks experienced by the patient but (although loquacious) he was a poor witness. It was not established that his were identical with the patient's-he had unilateral sensations but there was no definite precipitation by movement. Nevertheless there were some interesting similarities in his story and a familial incidence is well recognised.

He has congenital nystagmus. Aged 13 years he was concussed but recovered fully. Aged 17 he had his first attack, like his son while riding a bicycle, in which consciousness was lost. He was afterwards in an epileptic colony for three months where he had five "fits" but in which consciousness was not affected. Since that time he has been continuously on anticonvulsants (bromide, phenobarbitone or mysoline).

In 1957 he attended a hospital for nervous disease complaining of two sorts of attacks, sudden severe left temporal headache and tingling of the lefit face, arm and trunk. Clinical examination was normal and electroencephalogram is reported to have shown a generalised abnormality without paroxysmal disturbance. EEG was repeated at another hospital in 1962 following a fugue of two days after a drinking bout. There was "subnormal alpha slowing and mild excess of theta activity without specific epileptic pattern". Still on anticonvulsants, he has no complaints now and he is normal clinically.

\section{Discussion}

There seems no doubt that this condition is a distinct entity. It is commoner in young males, often affecting the leg more than the arm. Sudden activity or a surprise startle may initiate a tonic unilateral spasm of short duration, perhaps with a sensory aura. Some patients have spontaneous improvement (Matthews 1958) but in others the attacks become more frequent and most prefer to stay on phenobarbitone or epanutin indefinitely. A greater awareness of the distinctive features may lead to more cases being recognised.

Our thanks are due to Dr. K. W. G. Heathfield, who made the diagnosis, Dr. $O$. Garrod, under whose care the patient was admitted, and Dr. W. V. Stephenson, for access to the father and his records.

\section{REFERENCES}

Falconer, M. A., Drive, M. V. and Serafetinides, E. A. (1963): Seizures Induced by Movement: Report of a Case Relieved by Operation, J. Neurol. Neurosurg. Psychiat, 26, 300.

GOWERS, W. R. (1901): Epilepsy. London.

KISHIMOTO, K. (1958): Annual Report of the Research Institute, Nagoya University.

Lishman, W. A., SYMONDS, C. P., WhitTy, C. W. M., Willison, R. G. (1962): Seizures Induced by Movement, Brain, 85, 93.

MatTHEWS, W. B. (1958): Tonic Seizures in Disseminated Sclerosis. Brain, 81, 193.

WhitTy, C. W. M., Lishman, W. A., Fitzgibbon, J. P. (1964): Seizures Induced by Movement; a Form of Reflex Epilepsy, Lancet. ii, 1403.

Wilson, S. A., KINNIER (1930): The Third Morison lecture on Nervous Semeiology: Symptoms indicating Increase of Neural Function, Brit. med. J., ii, 90 . 